\title{
Serum Albumin Level Adjusted Progesterone Level on the Trigger Day is Not a Significant Predictor of Clinical Pregnancy
}

\author{
Cigdem YAYLA ABIDE ${ }^{1}$ Enis OZKAYA¹, Semra KAYATAS ESER ${ }^{1}$, Belgin DEVRANOGLU¹, Bulent Emre BILGIC ${ }^{1}$, \\ Tayfun KUTLU1 \\ Istanbul, Turkey
}

\begin{abstract}
OBJECTIVE: We aimed to assess the effect of serum albumin level adjusted progesterone levels on the trigger day on clinical pregnancy rate in intracytoplasmic sperm injection cycles.

STUDY DESIGN: A total of 100 women undergoing intracytoplasmic sperm injection cycles due to poor ovarian reserve or tubal factor infertility were included in this study. Serum progesterone and albumin levels on the trigger day were utilized to predict clinical pregnancy among normal and poor responders.

RESULTS: There were significant differences between groups with and without successful clinical pregnancy in terms of serum albumin (4.6 vs. $4.3 \mathrm{~g} / \mathrm{dL})$, progesterone levels $(0.5 \mathrm{ng} / \mathrm{mL} \mathrm{vs} .0 .7 \mathrm{ng} / \mathrm{mL})$ on the trigger day and endometrial thickness $(11.5 \mathrm{~mm}$ vs. $9.3 \mathrm{~mm})(p<0.05, p<0.05$ and $p<0.05$, respectively). In ROC analyses, progesterone level on the trigger day was found to be a significant predictor of clinical pregnancy (AUC=0.652, $p=0.015$ ). An optimal cut-off value of $0.55 \mathrm{ng} / \mathrm{mL}$ was obtained with $65 \%$ sensitivity and $57 \%$ specificity. However, after adjustment for progesterone and albumin levels, endometrial thickness was found to be significantly associated with successful clinical pregnancy $(\beta=0.39$, sig=0.038).
\end{abstract}

CONCLUSION: Progesterone action may be altered by albumin concentration, therefore albumin concentration should be taken into account to determine a cut off for premature progesterone rise.

Key words: Albumin, Implantation success, Clinical pregnancy, Progesterone, Trigger day

Gynecol Obstet Reprod Med 2018;24(2):87-91

\section{Introduction}

Premature luteinization often presents with elevated serum progesterone levels during controlled ovarian hyperstimulation (1). However, even in cases under LH suppression, significantly elevated serum progesterone levels may be observed in a subgroup of women (2).

Several studies have demonstrated that this issue is indica-

${ }^{1}$ Zeynep Kamil Maternity \& Children Education and Training Hospital Department of Reproductive Medicine and Infertility, Istanbul Turkey

Address of Correspondence: Cigdem Yayla Abide

Zeynep Kamil Maternity and Children's Health Training and Research Hospital, 34668 Istanbul, Turkey cigdemabide@gmail.com

Submitted for Publication: $\quad$ 05.01.2018 Accepted for Publication:

16.02 .2018

\begin{tabular}{|c|c|}
\hline \multicolumn{2}{|c|}{ Access this article online } \\
\hline 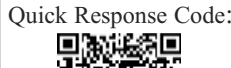 & $\begin{array}{l}\text { Website: www.gorm.com.tr } \\
\text { e-mail: info@gorm.com.tr }\end{array}$ \\
\hline 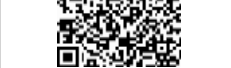 & DOI:10.21613/GORM.2017.771 \\
\hline
\end{tabular}

How to cite this article: Yayla Abide C. Ozkaya E. Kayatas Eser S. Devranoglu B. Bilgic BE. Kutlu T. Serum Albumin Level Adjusted Progesterone Level on the Trigger Day is Not a Significant Predictor of Clinical Pregnancy. Gynecol Obstet Reprod Med 2018;24(2):87-91 tive of both favorable and unfavorable outcomes in cases with premature increased progesterone (3-6). On the other hand, several studies have reported neither positive nor negative effects on outcome $(7,8)$. A study with a high number of cycles introduced a cut-off value for progesterone of greater than 1.2 $\mathrm{ng} / \mathrm{mL}$ as a significant predictor of poor outcome (3). It has been proposed that supra-physiologic serum concentrations of estradiol secondary to ovarian hyperstimulation may lead to a premature increase in progesterone, which may interfere with endometrial receptivity and result in implantation failure (9, 10). When released from steroidogenic cells, steroid hormones are mainly transported and presented in bound form. Most steroid hormones are bound to albumin; sex hormone-binding globulin, and corticosteroid-binding globulin while circulating in the blood. These proteins also have a function in regulating the non-protein-bound or 'free' forms (11). Reduced albumin concentrations caused by some systemic disorders, including reductions in severe malnutrition, cirrhosis, and nephrotic syndrome were reported to alter the plasma distribution of some steroid hormones (12).

The aim of this study was to assess the effect of serum albumin level adjusted progesterone levels on the trigger day on clinical pregnancy rates in intracytoplasmic sperm injection (ICSI) cycles. 


\section{Material and Method}

This retrospective, single-center cohort study was performed with infertile women who underwent assisted reproductive technologies (ART) treatment in the IVF clinic of Zeynep Kamil Women and Children's Health Training and Research Hospital, Istanbul, between July 2016 and November 2016.

All participants underwent an ICSI cycles antagonist protocol in the ART center and had regular menstrual cycles (menstruation occurring every $28 \pm 4$ days and lasting for about 5 days, with a physiological loss of approximately $30-70 \mathrm{~mL}$ of blood), normal serum prolactin levels and were without hormone treatment for 3 months. Patient ages ranged from 20 to 39 years old. All patients receiving assisted reproductive techniques were diagnosed with tubal factor infertility or poor ovarian reserve. Poor ovarian reserve was determined according to the following criteria: females over 35 years; a raised basal FSH level $>10 \mathrm{IU} / \mathrm{mL}$, irrespective of age; antral follicular count under 5 follicles; poor ovarian response or cycle cancellation in previous IVF cycle, irrespective of age. The definition of poor ovarian response in a previous cycle was oocyte yield under 5. Exclusion criteria were the cycle was cancellation due to failure of fertilization or poor embryo quality. After exclusion of 34 women with cycle cancellation, a total of 100 women undergoing ICSI cycles due to poor ovarian reserve or tubal factor infertility were included in this prospective study.

Follicle monitoring was performed by two dimensional sonographic measurements to observe growing follicles and calculate the mean value at each visit. An antagonist protocol was used in all cases. On the second day of the menstrual cycle, ampules of r-FSH (Gonal-FTM, Merck-Sereno, Geneva, Switzerland) 225-300 IU were administered and follicular growth was monitored using transvaginal sonography (TVUSG). The dosage of r-FSH was adjusted from day 5 of stimulation according to the ovarian response. Antagonist (Cetrorelix ${ }^{\mathrm{TM}}$, Merck-Sereno, Geneva, Switzerland) 0.25 $\mathrm{mg}$ /day was administered when the follicular size was $12 \mathrm{~mm}$. After the follicular size reached $18 \mathrm{~mm}, \mathrm{r}-\mathrm{hCG}$ (Ovitrelle ${ }^{\mathrm{TM}}$ $250 \mu \mathrm{g} / 0.5 \mathrm{~mL}$ Merck-Sereno, Geneva, Switzerland) was administered and follicular puncture was performed after 34-36 hours. Subsequently, 8\% vaginal progesterone gel (Crinone ${ }^{\mathrm{TM}}$ Merck-Sereno, Geneva, Switzerland) was used two times per day. Elective single grade 1 embryo transfer was done on the 3 rd or $5^{\text {th }}$ day in each case. Serum $\beta$-hCG level was measured after 2 weeks. Pregnancy was defined as a serum hCG level of $10 \mathrm{IU} / \mathrm{L}$ which observed 16 days after egg retrieval. The primary outcome was clinical pregnancy rate. Clinical pregnancy rate was defined as fetal heart beat(s) per transferred embryo.

\section{Hormone assays}

Blood samples were obtained on the day of $\beta$-hCG at 9-10 am for P4 level measurement and analyzed by radioimmunoassay with a sensitivity of $0.2 \mathrm{ng} / \mathrm{mL}$ (range of measure- ment was $0.2-40 \mathrm{ng} / \mathrm{mL}$ ). The within-assay variability was 7$10 \%(13)$.

Serum albumin assays were carried out using standard laboratory methods $(\mathrm{g} / \mathrm{dL})$.

\section{Statistical analysis}

Data were analyzed using SPSS 15.0 (SPSS. Inc., Chicago, Ill., USA) for Windows. Student $t$ test was used to compare continuous variables between the groups. Multivariate regression analyses were used to assess the adjusted associations. ROC analyses were used to assess the predictive value of the test and to calculate sensitivity and specificity. ANCOVA was used to compare adjusted means. P value $<0.05$ was accepted to be statistically significant.

\section{Results}

Among 100 cycles, there were 32 (32\%) subjects with successful clinical pregnancy. Among cases with blastocyst transfer $5(50 \%)$ cases had successful clinical pregnancy whereas among 90 cases with cleavage stage embryo transfers, successful clinical pregnancy was observed in $27(30 \%)$ cases ( $p$ $>0.05)$. Serum albumin $(4.5 \mathrm{~g} / \mathrm{dL}$ vs. $4.5 \mathrm{~g} / \mathrm{dl})$ and progesterone levels $(0.7 \mathrm{ng} / \mathrm{mL}$ vs. $0.5 \mathrm{ng} / \mathrm{mL})$ were similar between groups with two different stage of embryo transfers $(p>0.05)$. There were 41 women who fulfilled the criteria for poor ovarian response while 59 women were normoresponders. Comparison of demographic and ovarian stimulation characteristics of groups with and without successful clinical pregnancy are summarized in table 1 .

In ROC analyses, progesterone level on the trigger day was found to be a significant predictor of successful clinical pregnancy (AUC $=0.652, p=0.015$ ). An optimal cut-off value of $0.55 \mathrm{ng} / \mathrm{mL}$ was obtained with $65 \%$ sensitivity and $57 \%$ specificity (Figure 1). Albumin level adjusted progesterone concentrations on the trigger day were $0.67 \mathrm{ng} / \mathrm{mL}$ versus $0.64 \mathrm{ng} / \mathrm{mL}$, but this difference was not statistically significant $(p>0.05)$.

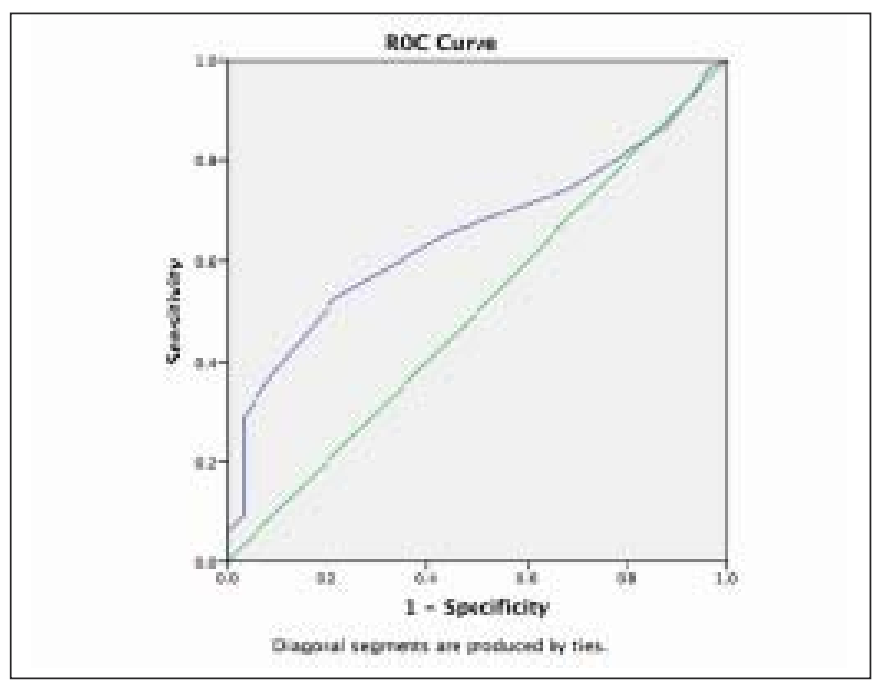

Figure 1: ROC curve analysis of the serum progesterone level 
In multivariate regression analysis, progesterone and albumin levels on the trigger day and endometrial thickness were included in the model. After adjustment for progesterone and albumin levels, endometrial thickness was found to be significantly associated with successful clinical pregnancy $(\beta=0.39$, $\operatorname{sig}=0.038)($ Table 2).

\section{Discussion}

In this study, we wanted to determine the clinical importance of albumin adjusted progesterone concentrations on the trigger day for clinical pregnancy following ART. Our data showed a significant association between progesterone concentration on the trigger day and clinical pregnancy; however, this association barely remained significant after adjustment of progesterone concentrations for serum albumin levels. Although the majority of studies have focused on the effect of premature progesterone rise on endometrial receptivity, there are some studies indicating a detrimental effect of progesterone on the oocyte (14). Additionally, several research studies have shown a critical role of albumin in maintaining the concentration gradient of steroids between the preovulatory follicular fluid and the circulation (15). Based on the afore- mentioned data, we reasoned that high albumin level could bind to progesterone and prevent its detrimental effect on the endometrium. However, this was not the case for the effect of progesterone on oocyte quality. In our data we partially excluded the effect of progesterone increase on oocyte quality by including the cycles with high quality embryo transfer. Premature progesterone rise during ovarian hyperstimulation is not a novel issue, but still an interesting one (7). Progesterone concentrations on the trigger day of more than $0.5 \mathrm{ng} / \mathrm{mL}$ were associated with a significantly lower rate of pregnancy (16). While there is data indicating similar pregnancy rates between groups with $\mathrm{p}<1.5 \mathrm{ng} / \mathrm{ml}$ versus $1.5-2$ $\mathrm{ng} / \mathrm{ml}$, authors suggest an optimal cut-off value of $\mathrm{p} \leq 2 \mathrm{ng} / \mathrm{ml}$ at the time of hCG (17).

Another cut-off value was proposed to be $\geq 1.2$ for the progesterone level on the day of hCG administration, with elevated pregnancy rates in polycystic ovary syndrome following a progesterone rise on the trigger day $(18,19)$. In other studies, different cut-off values were determined for negative effects of premature progesterone rise on pregnancy outcome, such as $\mathrm{p}=0.9 \mathrm{ng} / \mathrm{mL}, 1.0 \mathrm{ng} / \mathrm{mL}, 1.7 \mathrm{ng} / \mathrm{mL}$ and $1.99 \mathrm{ng} / \mathrm{mL}$ $(17,20-22)$. These variable results were proposed to be due to

Table 1: Comparison of demographic and ovarian stimulation characteristics of the study groups

\begin{tabular}{|c|c|c|c|}
\hline & $\begin{array}{l}\text { Successful Embryo Implantation } \\
\text { Mean } \pm \text { SD } \\
(n=32)\end{array}$ & $\begin{array}{l}\text { Failed Embryo Implantation } \\
\text { Mean } \pm \text { SD } \\
(n=68)\end{array}$ & $\begin{array}{l}{ }^{*} p \\
\text { Value }\end{array}$ \\
\hline Age (years) & $30.7 \pm 3.9$ & $31.4 \pm 4.0$ & NS \\
\hline BMI $\left(\mathrm{kg} / \mathrm{m}^{2}\right)$ & $25.4 \pm 3.4$ & $25.1 \pm 4.3$ & NS \\
\hline Duration of infertility (years) & $5.2 \pm 3.3$ & $6.1 \pm 3.2$ & NS \\
\hline $\mathrm{FSH}(\mathrm{IU} / \mathrm{mL})$ & $6.0 \pm 2.5$ & $6.1 \pm 2.1$ & NS \\
\hline $3^{\text {rd }}$ E2 (pg/mL) & $49.6 \pm 26.2$ & $47.6 \pm 29.4$ & NS \\
\hline AFC & $12.6 \pm 6.5$ & $12.3 \pm 5.8$ & NS \\
\hline Serum Albumin(g/dL) & $4.6 \pm 0.1$ & $4.3 \pm 0.2$ & $<0.05$ \\
\hline Trigger day P4 (ng/mL) & $0.5 \pm 0.2$ & $0.7 \pm 0.3$ & $<0.05$ \\
\hline Starting gonadotropin dose & $269.3 \pm 132.5$ & $254.5 \pm 84.5$ & NS \\
\hline Total gonadotropin dose & $2294.5 \pm 1245.7$ & $2364.3 \pm 921.0$ & NS \\
\hline Duration of stimulation (days) & $9.2 \pm 1.8$ & $9.3 \pm 1.6$ & NS \\
\hline Estradiol on trigger day & $1637.7 \pm 1004.2$ & $1514.2 \pm 722.5$ & NS \\
\hline Endometrial Thickness (mm) & $11.5 \pm 2.9$ & $9.3 \pm 0.8$ & $<0.05$ \\
\hline Total oocyte count & $6.1 \pm 2.2$ & $6.1 \pm 2.8$ & NS \\
\hline Mature oocyte count & $4.6 \pm 1.6$ & $4.6 \pm 2.1$ & NS \\
\hline Immature oocyte count & $1.5 \pm 0.5$ & $1.5 \pm 0.7$ & NS \\
\hline
\end{tabular}

Student $t$ test ${ }^{*} p<0.05$, BMI: Body mass index, FSH: Follicle stimulating hormone, E2: Estradiol, AFC: Antral follicle count, P4: Progesterone

Table 2: Multivariate regression analyses of serum progesterone, albumin levels and endometrial thickness on the trigger day

\begin{tabular}{lrrr}
\hline & $\beta$ & $t$ & Sig. \\
\hline Serum Albumin & 0.336 & 1.599 & 0.125 \\
Progesterone on trigger day & -.070 & -0.334 & 0.741 \\
Endometrial Thickness & 0.397 & 2.215 & 0.038 \\
\hline
\end{tabular}

Multivariate Logistic regression analyses 
different sample number and different methodologies for hormone measurement, different patient populations or even human error. A similar physiological function as we proposed for progesterone has been suggested in a previous study for serum calcium levels. It was suggested that adjustment of serum total calcium concentration for albumin was essential for detecting abnormal values and for assessing changes (23). Another proposed model to estimate steroid hormone effects is the free androgen index, which is utilized to determine the main effect of testosterone after adjustment for serum binding protein (24). A study conducted by Klebanoff MA showed that saliva is a valid substitute for plasma in assays of progesterone, even when concentrations of hormone and binding proteins are fluctuating. The authors concluded that salivary progesterone is a very good alternative to plasma for use in follow-up during pregnancy (25).

From this point of view and based on the data indicating a high level of progesterone bound to albumin, we conducted this study, and our data revealed no detrimental effect of albumin adjusted premature progesterone rise on clinical pregnancy in ovarian hyperstimulation cycles in which high concentrations of steroid hormones are released into the circulation.

In conclusion, this study showed that progesterone levels oscillate in a narrow range and this is affected by serum albumin levels. Albumin adjusted progesterone concentrations may be more appropriate for determining candidates for a freeze-all policy. This conclusion was drawn from the data of small sample size so requires verification by further studies with wider study population.

๙: Acknowledgement: None

Conflict of interest statement: The authors report no conflicts of interest.

Funding: None

\section{References}

1. Lindheim SR, Cohen MA, Chang PL, Sauer MV. Serum progesterone before and after human chorionic gonadotropin injection depends on the estradiol response to ovarian hyperstimulation during in vitro fertilization-embryo transfer cycles. J Assist Reprod Genet 1999;16(5): $242-46$.

2. Huang R, Fang C, Xu S, Yi Y, Liang X. Premature progesterone rise negatively correlated with live birth rate in IVF cycles with GnRH agonist: an analysis of 2,566 cycles. Fertil Steril 2012;98(3):664-70

3. Bosch E, Valencia I, Escudero E, Crespo J, Simon C, Remohi J, et al. Premature luteinization during gonadotropin-releasing hormone antagonist cycles and its relationship with in vitro fertilization outcome. Fertil Steril 2003;80(6):1444-49

4. Lee FK, Lai TH, Lin TK, Horng SG, Chen SC.
Relationship of progesterone/estradiol ratio on day of hCG administration and pregnancy outcomes in high responders undergoing in vitro fertilization. Fertil Steril 2009;92(4):1284-89

5. Kılıçdağ EB, Haydardedeoglu B, Cok T, Hacivelioglu SO, Bagis T. Premature progesterone elevation impairs implantation and live birth rates in GnRH-agonist IVF/ICSI cycles. Arch Gynecol Obstet 2010;281(4):747-52

6. Nayak S, Ochalski ME, Fu B, Wakim KM, Chu TJ, Dong $\mathrm{X}$, et al. Progesterone level at oocyte retrieval predicts in vitro fertilization success in a short-antagonist protocol: a prospective cohort study. Fertil Steril 2014;101(3):676-82

7. Saleh HA, Omran MS, Draz M. Does subtle progesterone rise on the day of HCG affect pregnancy rate in long agonist ICSI cycles? J Assist Reprod Genet 2009;26(5):23942.

8. Lai TH, Lee FK, Lin TK, Horng SG, Chen SC, Chen YH, et al. An increased serum progesterone-to-estradiol ratio on the day of human chorionic gonadotropin administration does not have a negative impact on clinical pregnancy rate in women with normal ovarian reserve treated with a long gonadotropin releasing hormone agonist protocol. Fertil Steril 2009;92(2):508-14

9. Kutlu T, Ozkaya E, Ayvaci H, Devranoglu B, Sanverdi I, Sahin Y, et al. Area under curve of temporal estradiol measurements for prediction of the detrimental effect of estrogen exposure on implantation. Int J Gynaecol Obstet 2016;135(2):168-71.

10. Ozkaya E, Kutlu T, Yayla CA, Eser SK, Sanverdi I, Devranoglu B. Area under curve of temporal estrogen and progesterone measurements during ART: Which hormone is the main determinant of cycle outcome? J Obstet Gynaecol Res 2018;44(2):263-9

11. Siiteri PK, Murai JT, Hammond GL, Nisker JA, Raymoure WJ, Kuhn RW. The serum transport of steroid hormones. Recent Progress in Hormone Research. 1982; 38:457-510

12. Dunn JF, Insula BC, Rodbard D. Transport of steroid hormones: Binding of 21 endogenous steroids to both testosterone-binding globulin and corticosteroid-binding globulin in human plasma. J Clin Endocrinol Metab 1981; 53(1):58-68

13. Saharkhiz N, Salehpour S, Tavasoli M, Aghighi A. Premature progesterone rise at human chorionic gonadotropin triggering day has no correlation with intracytoplasmic sperm injection outcome. Iran J Reprod Med 2015;13(2):79-84.

14. Huang B, Ren X, Wu L, Zhu L, Xu B, Li Y et al. Elevated Progesterone Levels on the Day of Oocyte Maturation May Affect Top Quality Embryo IVF Cycles. PLoS One.2016:8;1(1):e0145895

15. Lyons RA, Saridogan E, Djahanbakhch O. The effect of ovarian follicular fluid and peritoneal fluid on Fallopian tube ciliary beat frequency. Hum Reprod 2006;21(1):52-6 
16. Schoolcraft W, Sinton E, Schlenker T, Huynh D, Hamilton F, Meldrum DR. Lower pregnancy rate with premature luteinization during pituitary suppression with leuprolide acetate. Fertil Steril 1991;55(3):563-6.

17. Ochsenkuhn R, Arzberger A, von Schonfeldt V, Gallwas J, Rogenhofer N, Crispin A, et al. Subtle progesterone rise on the day of human chorionic gonadotropin administration is associated with lower live birth rates in women undergoing assisted reproductive technology: a retrospective study with 2,555 fresh embryo transfers. Fertil Steril 2012;98(2):347-54

18. Rezaee Z, Ghaseminejad A, Forootan M, Hosseinipoor T, Forghani F. Assessment of Serum Progesterone Level on the Day of hCG Injection in Infertile Polycystic Ovarian Syndrome Patients Referred to Women's Hospital, Tehran. 2009. Int J Fertil Steril 2012;5(4):231-4.

19. Ghaseminejad A, Rezaee Z, Forootan M, Hosseinipoor T, Forghani F, Nikuei P. Effect of predictive value of progesterone level on the day of HCG injection for IVF success in women with infertility due to tubal factor or polycystic ovarian syndrome referred to the women hospital, Tehran, 2009. Iran J Reprod Med 2012;10(4):349-54.

20. Check JH, Lurie D, Askari HA, Hoover L, Lauer C. The range of subtle rise in serum progesterone levels following controlled ovarian hyperstimulation associated with lower in vitro fertilization pregnancy rates is determined by the source of manufacturer. Eur J Obstet Gynecol Reprod Biol 1993;52(3):205-9.

21. Lahoud R, Kwik M, Ryan J, Al-Jefout M, Foley J, Illingworth P. Elevated progesterone in GnRH agonist down regulated in vitro fertilization (IVF-ICSI) cycles reduces live birth rates but not embryo quality. Arch Gynecol Obstet 2012;285(2):535-40

22. Fanchin R, de Ziegler D, Taieb J, Hazout A, Frydman R. Premature elevation of plasma progesterone alters pregnancy rates of in vitro fertilization and embryo transfer. Fertil Steril 1993;59(5):1090-4

23. Dalmar A, Raff H, Chauhan SP, Singh M, Siddiqui DS. Serum 25 hydroxyvitamin D, calcium, and calcium-regulating hormones in preeclamptics and controls during first day postpartum. Endocrine 2015;48(1):287-92

24. Dickerson EH, Cho LW, Maguiness SD, Killick SL, Robinson J, Atkin SL. Insulin resistance and free androgen index correlate with the outcome of controlled ovarian hyperstimulation in non-PCOS women undergoing IVF. Hum Reprod 2010;25(2):504-9

25. Klebanoff MA, Meis PJ, Dombrowski MP, Zhao Y, Moawad AH, Northen A, et al. Salivary progesterone and estriol among pregnant women treated with 17-alpha-hydroxyprogesterone caproate or placebo. Am J Obstet Gynecol 2008;199(5):506 